voltages. There is a substation on the ground floor, and the Corporation of Exeter supplies 210 volts twophase alternating current, which is distributed for light and power. In addition, there is a 200 volts direct current generator and an alternator, the latter supplying alternating current of variable voltage and frequency.

For the supply of compressed air and of vacuum the unit system has been preferred to that of general distribution, and any worker who requires either of them has it thus under his own control. The machines in the workshop are entirely unit driven, and there is a small furnace for casting. An automatic domestic telephone service is installed in a number of rooms.

The ground floor contains the workshop, battery and dynamo rooms, a small magnetic laboratory, two theatres, preparation and research rooms, a spectroscopy laboratory, and cloakrooms. The larger theatre, which has seating for 150 as a minimum, is fitted with electrically controlled light-tight blinds, and the smaller theatre, which adjoins it, is provided with a minimum seating for 80 . The acoustic properties of both theatres have received particular consideration, and the demonstration benches are anti-vibrational, being supported on a layer of concrete, $2 \mathrm{ft}$. thick, embedded in the ground and separated from the floor. The fixed slate benches in the spectroscopy laboratory and in some of the research rooms are also anti-vibrational.

The first floor is similar in construction and contains a large laboratory for advanced students, intermediate and advanced optics rooms, honours laboratory; private, research, glass-work, apparatus, and store rooms; together with a large laboratory for intermediate students. There is also a writing-room and a library, jointly used by the students of chemistry and physics. Except in the intermediate laboratory, there are no fixed benches on the floors, those around the walls being built on brick piers which rest on the concrete floor. These wall benches are of solacite-an acid-and heat-resisting material similar to slate. A special feature of the physics department is the provision of numerous electrical panels in all rooms, so that each student has available, on one and the same panel, lighting, power, and direct current (variable voltage) circuits. This arrangement has already proved of the greatest value and convenience.

The chemistry department occupies the whole of the second floor. A feature is the junior laboratory-a spacious room about $80 \mathrm{ft}$. long and $35 \mathrm{ft}$. wide-for intermediate and pass degree students. It has places for forty-eight students. There are also laboratories for physical, analytical, and organic chemistry, two lecture theatres - similar to those on the ground floortogether with preparation and store rooms. In addition, there is a number of small rooms which have been especially adapted for research.

Flats above the second floor are provided for the caretaker and resident engineer, while a portion of the roof is flat and available for special experiments. An automatic lift completes the equipment.

Owing to the national situation, no official opening has been held, but last December the Physics Department, in conjunction with representatives of the electrical industry, organised a three-days' Faraday exhibition, at which Sir William Bragg gave the inaugural lecture. This exhibition, which was attended by some five thousand people, enabled the general public to inspect the laboratories, the erection of which emphasises the rapid progress and development of the College, situated as it is in a non-industrial area.

\title{
Developments of Electric Lighting
}

$\mathrm{I}^{\mathrm{N}}$ the February number of the G.E.C. Journal there is an interesting article by $\mathrm{H}$. W. Richardson on the progress and development made by the General Electric Company in 1931. Considerable progress has been made in perfecting striated discharge tubes for lighting. In all ordinary discharge tubes containing rare gases, the glow in the main part of the tube is continuous. When, however, common gases such as air or nitrogen are used, the discharge, under certain conditions, breaks up into a number of separate sections. This effect is known as the striated discharge. Formerly it was only possible to get this effect momentarily. As a result of recent work in the G.E.C. laboratories, this type of discharge can now be produced at will in neon, and the effects are very striking and beautiful. It is still in the experimental stage.

In addition, new colours in cold cathode tubes such as are used for advertising purposes have been developed. Hot cathode tubes, the intensity of the light from which is much greater than that of the older cold cathode type, have not yet reached the commercial stage, but development is proceeding very satisfactorily. Owing to their high efficiency as sources of coloured light, they possess special attractions for use in coloured flood-lighting and for coloured lighting generally. By suitable combinations of coloured sources, light for general illumination can be produced. In combination with ordinary incandescent lamps they give light almost indistinguishable from daylight. The absolute efficiency of the conversion of light into power is now very high. The new so-called "ripple" effect was described in the Journal two years ago. At the time, this effect could only be obtained in blue or green colours. It has now been possible to produce it in neon gas so as to give the well-known orange hue.

The G.E.C. laboratories have carried out a large amount of work in connexion with aviation lighting equipment. A reflector type air beacon has been developed which on trial gave results closely approximating to the predetermined calculations. In the new aerodrome flood-light there are nine reflectors of parabolic trough formation each equipped with 1000 watt tubular lamps. With the help of a specially developed focusing device, the unit can be set up in daylight. The results obtained by tests at night are very satisfactory.

During the past three years commercial photometry has been passing through a transition stage. All the visual methods used during the last forty or fifty years are steadily being superseded by photoelectric methods of measurement. Three photoelectric photometers are at present in use at the G.E.C. Research Laboratories which are capable of being used for several purposes. They can, for example, measure the lumens on a direct reading lumen scale over a range of colour temperatures extending from $2400^{\circ} \mathrm{K}$. (absolute) to $2800^{\circ} \mathrm{K}$. approximately. The lumens and colour measurements are both measured on direct reading scales, and so also are the measurement of lumens and lumens per watt. These improvements save a great deal of time and greatly reduce the risk of error. At the Osram lamp works a photoelectric photometer utilising a cubical photometric integrator of eight-foot side has been installed. It has been designed more especially for the measurement of the very large lamps used in lighthouses, which often require 10,000 watts each.

No. 3254 , VoL. 129] 